\title{
Health Related Quality of Life and Wellness of Aging LGBT Populations in Wilmington and the Cape Fear Coast
}

\author{
Noell L Rowan ${ }^{1 *}$, Ph.D., LCSW, LCAS and Angela L. Wadsworth², Ph.D. \\ ${ }^{1}$ Professor and Associate Director, University of North Carolina Wilmington, USA \\ ${ }^{2}$ Senior Lecturer, Department of Sociology and Criminology, University of North Carolina Wilmington, USA
}

*Corresponding author: Noell L Rowan, Professor and Associate Director, Coordinator, BSW Program Coordinator, Substance Use Disorders and Addictions Certificate Program, School of Social Work, College of Health and Human Services, University of North Carolina Wilmington, Office: 3025 McNeill Hall, 601 South College Road, Wilmington, NC 28403, USA

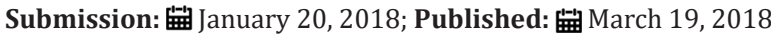

\section{Introduction}

Estimates consistently state that by $2030,20 \%$ of the U.S. population will be age 65 and older, a total of 70 million elders [1,2]. Within this group, older LGBT persons are predicted to number 1.75 to 3.5 million, "with approximately 500,000 gay men and lesbians turning age 50 each year" [1,3]. Goldsen \& Kim [4] report an estimate of more than 2.4 million adults in the United States ages 50 and older identify as lesbian, gay, bisexual, or transgender (LGBT). Cultural ageism and heterosexism, along with fear of discrimination at the hands of health care providers in inpatient and outpatient, short-term as well as long-term care settings, can and often do have a direct negative effect on the quality of life of older LGBT persons $[1,3,5]$.

Issues pertaining to getting older combined with a history of marginalization and discrimination elevates the heightened risks for discrimination and health disparities for LGBT older adults. Older lesbian, gay, bisexual, and transgender adults face risks of significant health disparities. They are less likely to disclose their sexual orientation or gender identity and to seek medical care because of fear of discrimination and cost of services [6-8], thus increasing risk of medical conditions worsening and becoming more difficult and costly to treat once services are sought. "One of the main features of social exclusion of LGBT people is their invisibility and marginalization, or in more political terms, the lack of recognition of LGBT people as full members of a community and as citizens" [9].

Despite the increased visibility of LGBT older adults due to proliferating media coverage about LGBT populations of various age groups [10], considerable work is called for to ensure culturally relevant services to the estimated two to seven million LGB and T older adults over the next few decades. There are many training curricula to increase cultural sensitivity of service providers who work with LGBT older adults [11]. The National Resource Center (NRC) on LGBT aging likely has the broadest reach after federal funding was awarded to create Services and Advocacy for GLBT
Elders (SAGE) in partnership with many nationwide organizations [12]. The aim of the NRC and SAGE affiliates is to improve the lives of LGBT older adults through culturally sensitive training and services for service providers. Improving the health and wellness of aging LGBT people has been listed as a priority by US Department of Health and Human Services [13] and significant progress has begun.

The rationale for this study is based on recent survey findings of aging LGBT populations in the Cape Fear Region of the North Carolina Coast [14]. The main purpose of the survey was to examine the potential relationship between LGBT respondents in the geographic region and issues about health care. The LGBT sample had a total of 223 respondents with a mean age of 50.58 ( $S D=14.89$ ). Survey results indicated a need for more culturally sensitive health provisions with requests for LGBT specific social activities (66\%), recreational or wellness activities (52\%), and art and cultural activities (50\%) [14]. These results are in keeping with prior research showing interest in cultural and physical exercise opportunities such as yoga, exercise classes, etc. [5]. Moreover, Mule et al. [15] emphasized the importance of addressing the wellbeing for LGBT persons in an effort to improve health care provisions. Given these findings, this study was created based on the work on the authors parts to engage in the community with the local Foundation (Frank Harr Foundation) which serves the LGBT community and the Services and Advocacy for the GLBT Elder populations (SAGE) affiliate in the Wilmington Cape Fear Coast Region of North Carolina, and support from a community engagement grant sponsored by the authors' institution. The purpose of the study was to learn more about the ways to improve wellness and overall health related quality of life of LGBT adults in this regional area.

While quality of life has been defined as "the ability to enjoy opportunities in the human life process under equity conditions; health related quality of life is related to an adequate access to 
health services [16]. Neither can exist without the other. This is particularly relevant for older LGBT persons, who are more likely to find themselves dealing with discrimination as they interact more often with health care personnel as part of the aging process. Both health care providers and LGBT persons agree that quality of life is "linked to the guarantee of access and enjoyment of basic goods and services" [16]. Homophobic experiences have been associated with negative effects on quality of life of LGBT persons [16]

Prior research by Fredriksen-Goldsen et al. [17] has identified that "health-promoting behaviors, including physical activity, leisure activity, and substance nonuse, are related to better physical and mental health quality of life across all age groups". There is an increased awareness that leisure space serves an important purpose for gays and lesbians, offering an opportunity for physical, mental, and emotional "recharging" that facilitates the building of stress coping tools and improving quality of life [17]. These prior studies provide the rationale for this research to explore about ways to improve wellness and overall health related quality of life of LGBT adults.

\section{Methods}

In order to measure health related quality of life, the authors used one measure for pre and post evaluation. The Centers for Disease Control measure on health related quality of life (HRQOL-14 "Healthy Days Measure") was utilized for this study. The measure is a 14 item scale of general health related quality of life of young and older adults. The HRQOL has shown good construct validity and acceptable correlation with related SF-36 scales [18]

This research study was approved by the Institutional Review Board (IRB) of the authors' institution and was supported by a community engagement grant sponsored by the authors' institution. Recruitment was initiated with our community partners, Frank Harr Foundation and SAGE Wilmington of the Cape Fear Coast. These two community partners specifically reach out to members of the LGBT populations in the Cape Fear region of North Carolina. Recruitment flyers and email blasts were sent through the community partner email lists, Face book, and website in addition to postings in local community event locations hosted by the community partners. There were two in person recruitment events held in a local restaurant private patio area for purposes of explaining the study and giving time for questions and answers about the informed consent process.

Study participants signed the informed consent and completed the pre-test of the HRQOL-14 and were given the opportunity to choose between two wellness groups, a walking group or a yoga group. The participants were asked to select participation in three consecutive one hour sessions of a walking group (held in a local park and guided by one of the members of the supporting organizations) or a yoga group (low impact; held in a private yoga studio and led by a certified yoga instructor). Upon completion of the third walking or yoga group, participants were asked to complete the HRQOL-14 post test. Participants who completed all three walking or yoga groups were invited to attend a complimentary community cultural event, a play held in a local downtown theatre. The play was held the next evening after completion of the third walking or yoga group sessions and was offered as an incentive for completing the study requirements and as another opportunity for social interaction amongst members of the LGBT community.

\section{Description of the Sample}

The sample for this study consisted of a total of eleven $(\mathrm{N}=11)$ persons identifying as lesbian (5), gay (5) or bisexual (1). The age of the sample ranged from 28-75 with a mean age of 67.3 ( $S D=5.3$ ) and $81.8 \%$ of the sample were age 48 and over. There were no identified transgender participants in this sample. Five participants identified as male and six participants identified as female. All of the participants indicated that their health was good, very good or excellent. Specific health concerns were indicated by the participants with arthritis/rheumatism ( $\mathrm{N}=3 ; 42.86 \%)$, back or neck issues $(\mathrm{N}=2 ; 28.57 \%)$, lung/breathing concerns $(\mathrm{N}=1 ; 33.33 \%)$, and eye/vision concerns $(\mathrm{N}=2 ; 33.33 \%)$. Only one participant indicated needing help from others to do personal care and two participants indicated needing help from others with daily chores. Four out of six participants that chose the walking group intervention indicated that they had participated in a walking group prior to the study and only one out of five participants that selected the yoga group intervention had ever tried a yoga group practice prior to the study.

\section{Analysis}

A Wilcoxon on Sign Rank Sum test was utilized for this study to compare results from the HRQOL-14 measure from pre to post test. This analysis was conducted to provide an understanding of how the participants indicated their health pre and post in the study with the walking vs. yoga group comparison. This Wilcoxon on Sign Rank Sum t test was chosen because it is equivalent to at test for comparison of pre and post analysis but is more appropriate for the smaller sample size from this study.

\section{Results}

Table 1 displays the frequencies from pretest and posttest walking and yoga group participants. The Wilcoxon Sign Rank Sum test for length of time (number of days) of having physical pain, length of time of not enough rest/sleep, and length of time of feeling very healthy/full of energy from pretest to posttest did not indicate significant findings between the two intervention groups using the HRQOL-14. Table 2 demonstrates the significant results of Wilcoxon on rank sum sign test at posttest for length of time (in number of days) for length of sadness/depression and length of worriedness. These data show that there is a significant difference between walking group and yoga group participants. The yoga group participants had less days of sadness/depression $(p=0.0225)$ and worriedness $(\mathrm{p}=0.0141)$ when compared with the walking group participants after the intervention. Both intervention groups indicated a decrease in the number of days of all health measures which included length of pain, sadness/depression, worriedness, 
not enough rest/sleep at posttest. Moreover, all participants indicated an increase in length of days feeling very healthy/full of energy. There was also a decrease in the number of participants needing help from others with daily chores and with personal care with one participant in the walking group and one participant in the yoga group needing this help prior to the intervention and no longer needing help after the intervention.

\section{Qualitative findings}

Participants were asked two open ended questions at post test only to enhance understanding of the benefits and limitations of the wellness groups. The first question was: What did you appreciate about this wellness activity? This question generated responses from every participant in both groups. The yoga group participant responses were very positive about the benefits of the yoga activity. Some examples include an appreciation of the stress free environment, an approachable instructor, and an enjoyment of doing yoga with their spouse and feeling more relaxed and stretched out. Walking group participants comments were very positive also about the benefits of walking as a community and enjoyment of the socialization and fellowship. The second question was: What did you feel was not beneficial about this wellness activity? There were not many comments on what was not beneficial except for the time of day or that the activity did not last enough weeks.

\section{Discussion}

This is the first comparison group study with older LGB adults in this region of North Carolina with special emphasis on health concerns. The findings reveal that conducting wellness interventions for these populations can demonstrate a decrease of indicators of health related concerns and an improvement in health related quality of life. The qualitative findings were very positive with most responses appreciating the wellness activity that they were involved in for reasons of stress reduction, skill level of yoga instructor, and accessibility of instructor, and social support aspects of walking group and ability to join in exercise with their spouse and other members of the LGB community. The benefits of both wellness groups were clearly related to a more positive outlook in engaging in wellness activity with other people with a sense of community in a relaxed atmosphere. Several participants noted the appreciation of the connection with other people, the enjoyment of wellness activity, feeling more energy and socialization. The nonbeneficial comments of the wellness activities were few and mostly were desires for longer periods of time to participate in the yoga activity and perhaps a different time of day for the walking group.

The quantitative findings indicate at post test measure, that the participants had improved health outcomes with more days of feeling very healthful and full of energy and less days of pain, sadness/depression, worriedness, and not enough sleep/rest. Even though the yoga group showed significantly better health outcomes at post test than the walking group, both groups demonstrated improved health related quality of life outcomes.

As part of the discussion about this study, a brief description is included about the recent political climate in North Carolina.
The political climate may have impacted study participation and specific reach to older transgender persons in the local area.

From 1995-2009, Governor McCrory served as mayor of Charlotte, the state's largest city, stepping down in 2009 to run successfully for the office of governor. The timing of passage of HB2 is believed to be a direct reaction to the fact that a few weeks earlier, Charlotte's mayor and city council had passed a nondiscriminatory bill for citizens of their municipality. Among other protections, this Charlotte bill insured the rights of LGB and T persons.

On March 23, 2016, House Bill 2 [19] was ratified by the N.C. Senate and House of Representatives and signed into law by Governor Pat McCrory, with McCrory staying in his office late that night to sign the bill into law at 9:57 p.m. This Bill, referred to as HB 2 or "the Bathroom Bill", makes it illegal for persons to use public bathrooms and changing facilities that are not in keeping with their biological sex. Additionally, the bill disallowed the establishment of living wages by any county or municipality in North Carolina, seized control of discriminatory employment practices, and denied individuals the right to sue due to discrimination. While there have been minimal revisions to the original HB2 bill since its passage, its discriminatory focus on LGB and T persons has been preserved. Reaction to the passage of HB2 was swift. Various artists and entertainers announced boycotts, with some choosing to honor prior performance commitments but donating proceeds to state LGB and T rights groups. The NBA and NCAA pulled championship games scheduled to occur in Charlotte or other locations in North Carolina in direct protest of the bill. The overall economic impact of HB2 was placed conservatively at 400 million dollars [20-22].

Given this backlash, and following the election of a Democratic Governor, Roy Cooper, in November 2016; efforts to repeal HB2 resulted in a legislative compromise passed on March 30, 2017-House Bill 142. While House Bill 142 is termed a repeal of HB2, a key issue for the LGBT community is that North Carolina will not allow local communities or municipalities to regulate public accommodations or private employment practices until December 1,2020 [23].

Another factor is that North Carolina is an employment at will state [24], meaning that for any number of reasons a worker can have their employment terminated. Chief among those reasons can be LBG and T identity. There is no protection under federal employment law for LGB and T persons regarding discrimination in the state of North Carolina, such protection has never existed. Additionally, LGB and T persons have no protection under federal hate crime legislation in the state of North Carolina.

It is impossible to ignore the effect of the political and social climate any time research is conducted, particularly with studying groups that are historically marginalized. LGB and T individuals in this age cohort lived and continue to live in a social location where identity status may require careful management of work, home, and social lives. Time and experience have taught LGB and $\mathrm{T}$ individuals of this age cohort that unsuccessful identity management can lead to consequences, "from being denied respect 
to being the target of harassment or violence" [25]. The effect of this recent discriminatory state legislation cannot be overstated. Disenfranchisement of LGB and T persons has been reified and codified in state law, a law that has yet to be overturned. We feel this likely had an impact on willingness of individuals to participate in the study, as well as affecting our efforts at recruitment and outreach.

\section{Study Limitations}

This study is limited given the small sample size and being located in a small geographic region of the eastern United States. Therefore, the results are not generalizable to all LGB older adult populations due to a limited sample. This LGB sample in the coastal area of North Carolina are mostly hidden and understudied making generating high numbers in a wellness comparison study very challenging. Despite these barriers, the study did show some statistically significant difference with a wellness intervention.

\section{Conclusion}

Overall, there have been few studies exploring wellness activity within the LGB aging community and this is the first of its kind in the North Carolina coastal region. Despite the limitations of low sample size from a small specific geographic region and limited to LGB adults without members of the transgender adult community, there are valuable outcomes within this study. The results indicate that wellness interventions can make a positive impact on the health related quality of life in these LGB population groups. There is also a clear request for coming together to participate in both wellness and social activities with members of the LGB community. Implications from this research are to continue to explore ways to improve wellness among LGB older adults and to engage members of the transgender older adult community.

\section{References}

1. Landers S, Mimiaga MJ, Krinsky L (2010) "The Open Door Project Task Force: A Qualitative Study on LGBT Aging". Journal of Gay \& Lesbian Social Services 22(3): 316-336

2. Ortman JM, Velkoff VA, Hogan H (2014) An Aging Nation: The Older Population in the United States, Current Population Reports, Census Bureau, Washington DC, USA, pp. 25-1140.

3. Burda JM (2013) Changing Times for LGBT Seniors. GPSolo 30(4): 2933.

4. Fredriksen Goldsen KI, Kim HJ (2014) Count me in: Response to sexual orientation measures among older adults. Res Aging 37(5): 464-480.

5. Brennan Ing M, Seidel L, Larson B, Karpiak SE (2014) "Social Care Networks and Older LGBT Adults: Challenges for the Future". J Homosex 61(1): 21-52.

6. Fredriksen Goldsen KI, Kim HJ, Emlet CA, Muraco A, Erosheva EA, et al. (2011) The aging and health report: Disparities and resilience among lesbian, gay, bisexual, and transgender older adults. Seattle, Institute for Multigenerational Health, USA.
7. Fredriksen Goldsen KI, Hoy Ellis CP, Goldsen J, Emlet CA, Hooyman N (2014) Creating a vision for the future: Key competencies and strategies for culturally competent practice with lesbian, gay, bisexual, and transgender (LGBT) older adults in the health and human services. J Gerontol Soc Work 57(2-4): 80-107.

8. Rowan NL, Butler SS (2014) Resilience in attaining and sustaining sobriety among older lesbians with alcoholism. Journal of Gerontological Social Work 57(2-4): 176-197.

9. Teliti A (2015) Sexual prejudice and stigma of LGBT people. European Scientific Journal 11(14): 60-69.

10. Knochel KA, Quam JK, Croghan CF (2010) Are old lesbian and gay people well served? Understanding the perceptions, preparation, and experiences of aging services providers. Journal of Applied Gerontology 30(3): 370-379.

11. Moone RP, Cagle JG, Croghan CF, Smith J (2014) Working with LGBT older adults: An assessment of employee training practices, needs, and preferences of senior service organizations in Minnesota. J Gerontol Soc Work 57(2-4): 322-334.

12. Meyer H, Johnston TR (2014) The National Resource Center on LGBT Aging provides critical training to aging service providers. Journal of Gerontological Social Work 57(2-4): 407-412.

13. US Department of Health and Human Services (2012) LGBT health and well-being coordinating committee report.

14. Rowan NL, Beyer K (2017) Exploring the health needs of aging LGBT adults in the Cape Fear Region of North Carolina. J Gerontol Soc Work 60(6-7): 569-586

15. Mule NJ, Ross LE, Deeprose B, Jackson BE, Daley A, et al. (2009) Promoting LGBT health and wellbeing through inclusive policy development. Int J Equity Health 8: 18

16. Alzate Urrea S, Agudelo Suarez AA, Monsalve Orrego JY, Londono Candanoza FL, Chinome Florez, et al. (2016) Self-Perceived Discrimination in LGBT Population in Oral Health Services. Medellin, Colombia: A Qualitative Approach. Global Journal of Health Science 8(12): 152-162.

17. Fredriksen Goldsen KI, Kim HJ, Shiu C, Goldsen J, Emlet CA (2015) Successful Aging among LGBT older adults: Physical and mental healthrelated quality of life by age group. Gerontologist 55(1): 154-168.

18. US Department of Health and Human Services Centers for Disease Control and Prevention (2000) Health-Related Quality of Life (HRQOL-14)

19. North Carolina General Assembly (2016) House Bill 2. Second Extra Session. Session Law 2016-3. House Bill 2.

20. Abadi M (2016) North Carolina has lost a staggering amount of money over its controversial 'bathroom law'. Business Insider, India.

21. Bort R (2016) A Comprehensive Timeline of Public Figures Boycotting North Carolina over the HB2 'Bathroom Bill'. Newsweek, London.

22. Gordon M, Price MS, Peralta K (2016) Understanding HB2: North Carolina's newest law solidifies state's role in defining discrimination. Charlotte Observer, USA.

23. Jarvis C, Campbell C, Bonner L (2017) NC Senate, House approve HB2 repeal compromise. Raleigh News and Observer, USA.

24. North Carolina Department of Labor (2017) Employment at will.

25. Seidman S (2010) The Social Construction of Sexuality. ( $2^{\text {nd }}$ edn), WW Norton \& Company Inc., New York. 


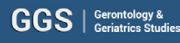

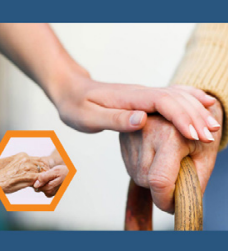

Gerontology \& Geriatrics Studies

Benefits of Publishing with us

- High-level peer review and editorial services

- Freely accessible online immediately upon publication

- Authors retain the copyright to their work

- Licensing it under a Creative Commons license

- Visibility through different online platforms

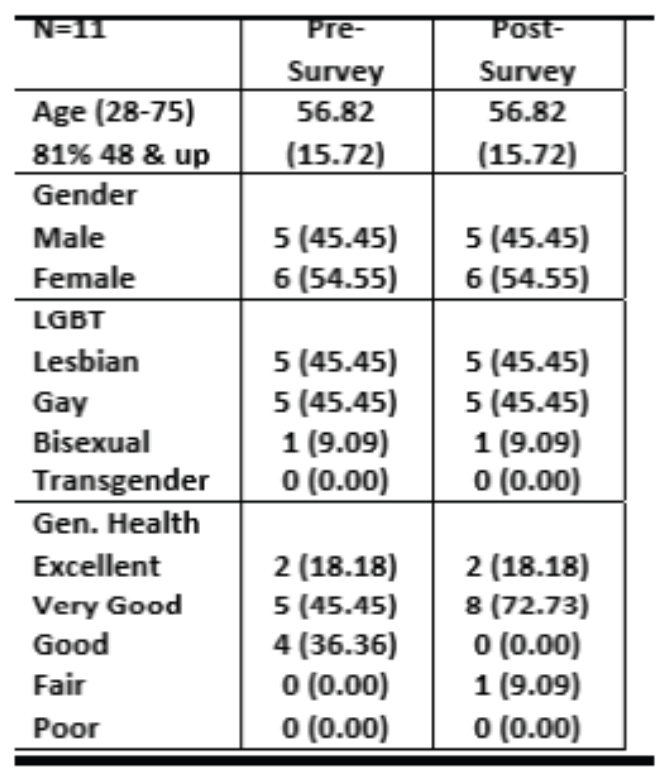

\begin{tabular}{l|l|l|l}
\hline Significant Results & $\begin{array}{l}\text { Mean } \\
\text { Post } \\
\text { Walking }\end{array}$ & $\begin{array}{l}\text { Mean } \\
\text { Post } \\
\text { Yoga }\end{array}$ & $\begin{array}{l}\text { P- } \\
\text { Value }\end{array}$ \\
\hline $\begin{array}{l}\text { Length of } \\
\text { Sadness/Depression }\end{array}$ & 7.17 & 3.0 & 0.0225 \\
\hline $\begin{array}{l}\text { Length of } \\
\text { Worriedness }\end{array}$ & 7.80 & 3.20 & 0.0141 \\
\hline
\end{tabular}

